\title{
Cores Produced by Geopolymer Technology and Impact to Casting Quality in Comparison with PUR Cold Box Amin
}

\author{
Michal Vykoukal ${ }^{1,2}$, Alois Burian ${ }^{1}$, Markéta Přerovská ${ }^{1}$, Milan Luňák ${ }^{3,4}$, Štefan Kyselka ${ }^{3}$ \\ ${ }^{1}$ SAND TEAM, spol. s r.o., Holubice 331, 68351 Holubice, Czech Republic. E-mail: vykoukal@sandteam.cz, bu- \\ rian@sandteam.cz,prerovska@sandteam.cz \\ ${ }^{2}$ VŠB - Technical University of Ostrava, Faculty of Materials Science and Technology, 17.listopadu 15, 70833 Ostrava, \\ Czech Republic \\ ${ }^{3}$ BENEŠ a LÁT a.s., Tovární 463, 28914 Poříčany, Czech Republic. E-mail: milan.lunak@benesalat.cz, stefan.ky- \\ selka@benesalat.cz \\ ${ }^{4}$ Faculty of Mechanical Engineering J. E. Purkyně University in Ústí nad Labem, Pasteurova 1, 40096 Ústí nad Labem, \\ Czech Republic
}

The article deals with geopolymer binder system for core production, especially by dehydration technology and comparison with PUR cold box amin technology. A sodium-potassium type of geopolymer binder is the subject of the research. The goal of the article is the core production and observing of technological properties, storing cores, usage of refractory coating evaluating of properties during the pouring and decoring of casting. The main target of the experiment is casting quality. It was stated that the final surfaces are much more better than PUR cold box amin technology and the internal casting quality is the same, it means without inadmissible internal defects. Worse decoring times were observed. It has been confirmed, that neither emissions, fumes nor unpleasant odours are generated during the production procedure nor during pouring.

Keywords: Geopolymer binder; Dehydration; Inorganic binder; Core; Environment.

\section{Introduction}

\subsection{Generally about geopolymers}

The geopolymers were discovered and terminology was introduced by Davidovits in the seventies of the last century [1]. Earlier in 1957 Gluchovskij investigated the problem of alkali-activated slag binders, he called the technology ,soil silicate concretes“ and the binders ,soil cements" [2]. These are materials that belong to alkaline aluminosilicates, so they are purely inorganic materials. The geopolymers contain silicon, aluminium and some alkaline element, such as sodium or potassium. In nature, such materials appear and are called zeolites. The geopolymers are not formed due to geological processes, they are artificially prepared and they are called so because their composition approaches natural rocks. The geopolymers consist of tetrahedron chains of $\mathrm{SiO}_{4}$ and $\mathrm{AlO}_{4}$ Fig. $1[1][3][4]$.

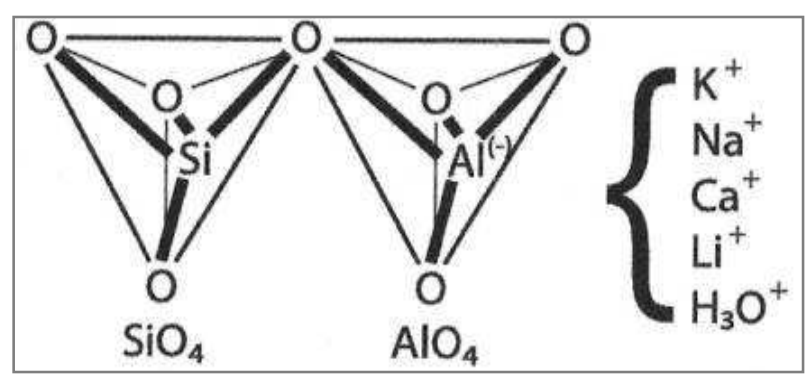

Fig. 1 The basic structural unit of geopolymers [1].

The geopolymers are the focus of interest in a number of industries. The ratio of the proportion of aluminium and silicon ranges from 1:1 to 1:35 (various ratios $\mathrm{SiO}_{4}$ and $\mathrm{AlO}_{4}$ tetrahedrons). According to the aluminium content varies the chemical and the physical properties of the resultant polymer, as well as its applications, diverse with the content of aluminium. The usage of geopolymers is extensive. Especially in the construction industry, these alkali-activated aluminosilicates are given considerable attention. In these applications, a geopolymer is formed during the process. The geopolymer is created in the reaction between the silicon-containing material and aluminium-containing material (fly ash, slag) and an alkaline activator. The resulting product has many advantages in comparison with the conventional materials. Geopolymers are, for example, also used in the solidification of hazardous waste, ceramics, and the refractory materials industry. Generally speaking, the main properties of the geopolymers which they are used, are fire resistance, high heat resistance, and low thermal expansion [1][3][4].

The geopolymers with a high molar ratio of $\mathrm{SiO}_{2} / \mathrm{Al}_{2} \mathrm{O}_{3}$, sometimes called geopolymer resins, are liquid substances with similar properties to colloidal solutions of alkali silicates - water glass. One of the possibilities for using geopolymer resins is a foundry binder. Either elevated temperatures or chemical way is used for hardening [3][5].

According to some archaeological publications, Egyptian pyramids are not of carved blocks but casted from the geopolymers and similarly Venus of Dolní Věstonice [1][5], there is an interesting idea.

\subsection{Geopolymers for foundry industry}

More and more emphasis is put on the clean and environment-friendly processes. Many foundries are exposed to a huge pressure. This leads to the introduction of new technologies, most often based on inorganic chemis- 
try, which are more acceptable in terms of the environment and sustainable development. The geopolymer binder systems and geopolymer technology are undoubtedly among these new technologies. A new environmentally friendly binder system has been developed using a geopolymer inorganic binder for the production of conventional moulds and cores in the Czech Republic. These polymers are also referred to polysialates and are composed of chains of tetrahedrons of $\mathrm{SiO}_{4}$ and $\mathrm{AlO}_{4}$ (Fig. 1).
The resulting properties of the binder depend on the ratio of these components and on the preparation of the geopolymer. The basic structural units consist of monomers, dimers and higher polymers.

The binder is an inorganic geopolymer precursor with a low degree of polymerization. The hardening occurs by the action of heat or hardeners. There is an increase in the degree of polymerization and formation of an inorganic polymer during the hardening reaction Fig. 2.

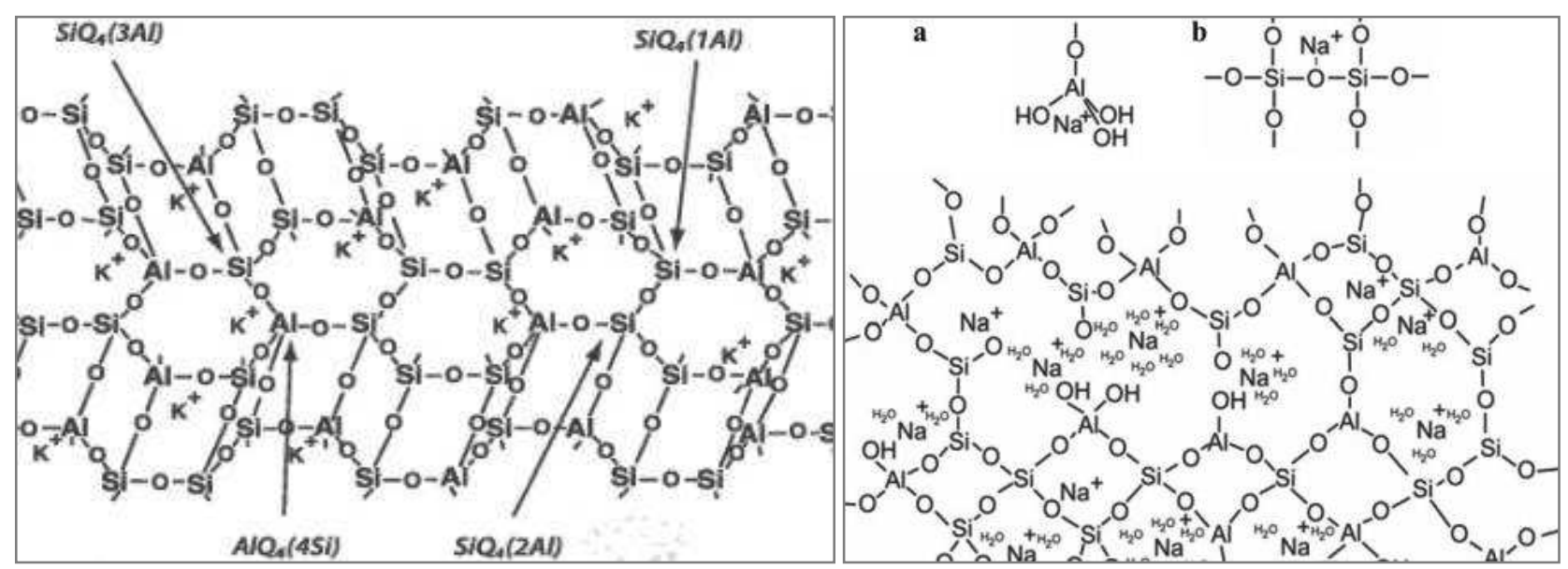

Fig. 2 Scheme and model of inorganic polymer by Davidovits (left) [1] and updated by Barbosa [6] and later by Rowles (right) [7].

The geopolymer technology hardened by dehydration is odourless technology and generates no pollutants, so it has a minimal negative impact on the environment. Due to the chemical nature of the geopolymer binder, the mechanical reclaimability of used sand mixture is feasible [3][8].

The emissions are one of the fundamental environmental troubles in foundries. Foundries have to take into account an increasing cost related to solving these environmental problems. They are increasingly interested in technologies with more favourable environmental characteristics and trying to introduce them into operation.
The environmental pressure is even greater in economically developed countries. There is also increased interest in the development of new technologies and their implementation [3].

In general, it is expected that the inorganic binder systems achieve significant reductions in emissions. The comparison of the binder systems from the point of view of the BTEX and the PAH shows in graphs in Fig. 3 [9].

The geopolymer technology is currently used in the foundries for three basic production processes/technologies: (1) self-hardening moulding mixtures, (2) sand mixtures hardened by gaseous carbon dioxide and (3) the hot box technology with hot air hardening [3].
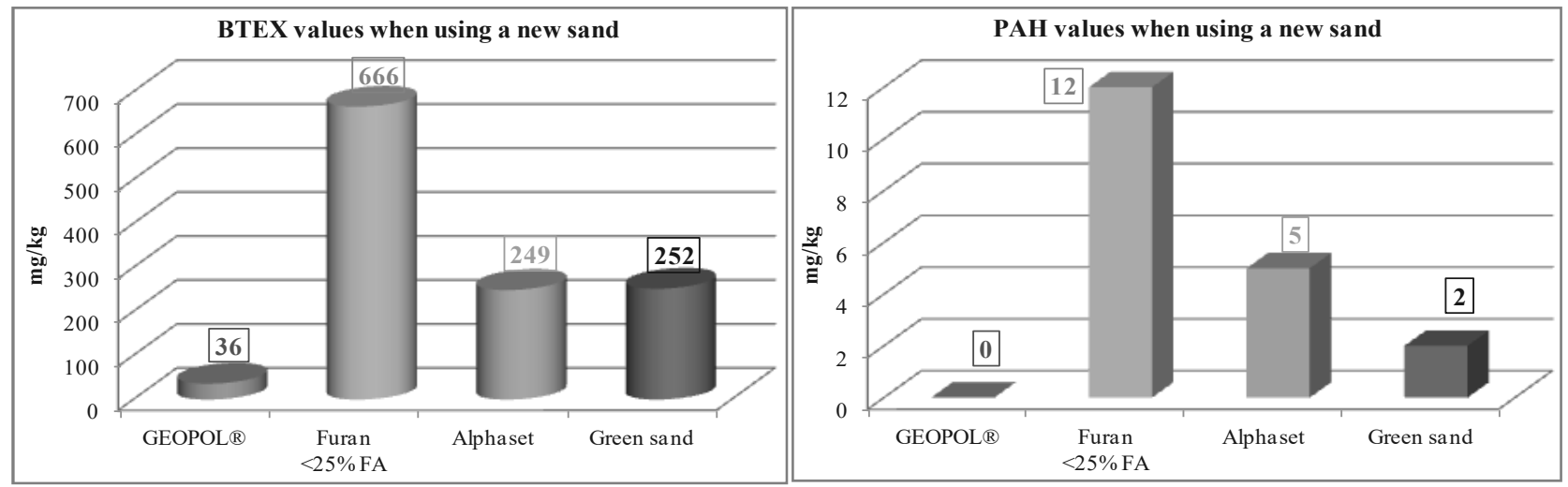

Fig. 3 Results of pollutant measurement during pouring, comparison of organic and inorganic binder systems [9].

\subsection{Hot box and hot air hardening, geopolymer tech- nology hardened by dehydration}

Geopolymer binders are used for the core production with hardening by heat. In this technology, the hardening is caused by dehydration, it means by a physical process. The technology is suitable for serial and mass core production. The whole technology is purely inorganic, thus it has a minimal impact on the environment and ensures favourable hygienic conditions [8]. 
The principle of this technology is as follows: the sand mixture is shot into a heated core box and the hardening of the sand mixture in the hot core box is speeded up by blowing the hot air through it at the same time. Suitable temperature of the core and the hot air ranges from 100 to $200{ }^{\circ} \mathrm{C}$. The temperature from 150 to $200{ }^{\circ} \mathrm{C}$ allows to obtain a long storage time and prevent the reverse cores hydration. Dehydration can also be achieved by microwave hardening [10].

It is recommended to use the GEOTEK powder additive, which has a beneficial effect on the reduced wettability of the cores and the increases the cold and hot strength of the cores [10].

When compared with PUR cold box amine technology, the comparable (higher) strengths are achieved at the same or shorter hardening time and the collapsibility of the cores after pouring is significantly better. Core strength and other properties depend on the addition level of the sand mixture and on the parameters of the production processes. Flexural strength after hardening and cooling reaches up to $5.5 \mathrm{MPa}$ [10][11].

The composition of the sand mixture for core production made by the geopolymer technology hardened by dehydration [11]:

- Sand. Generally quartz sand.

- Geopolymer binder, addition level ranging from 1.4 to $1.8 \%$, based on sand quantity (quartz sand).

- Accelerator GEOTEK W, addition level ranging from 0.3 to $0.9 \%$, based on sand quantity, generally $50 \%$ of binder weight.

Tab. 1 Addition level of geopolymer binder for technology hardened by heat on different foundry sands [11].

\begin{tabular}{|l|c|}
\hline \multicolumn{2}{|c|}{ Geopolymer technology hardened by heat } \\
\hline Foundry sand & $\begin{array}{c}\text { Range of addition level } \\
\text { [wt. \% on sand weight] }\end{array}$ \\
\hline Quartz sand & $1.4-1.8$ \\
\hline CERABEADS & $1.8-2.5$ \\
\hline $\begin{array}{l}\text { Addition levels of additive GEOTEK are from } 0.3 \text { to } \\
0.9 \% \text { based on sand. }\end{array}$ \\
\hline
\end{tabular}

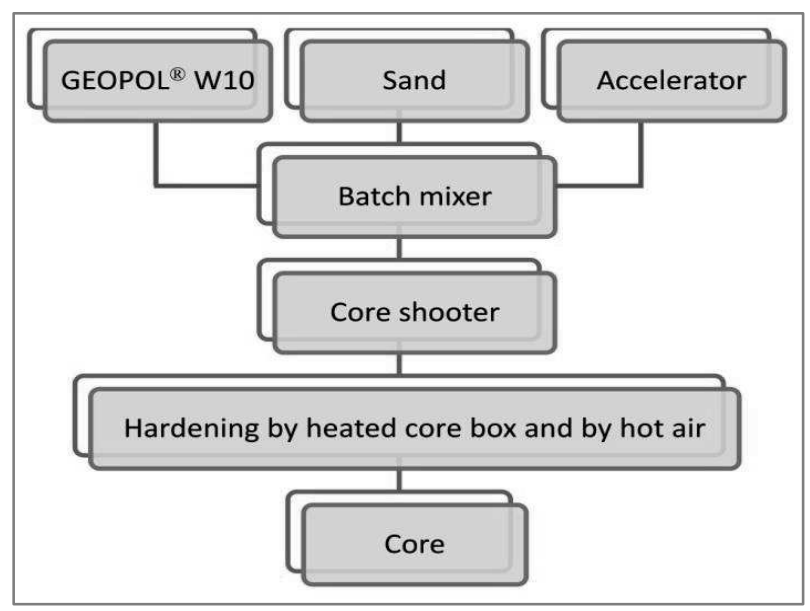

Fig. 4 Geopolymer core production scheme hardened by dehydration [11].
The addition of $1.8 \%$ of binder and $0.9 \%$ of accelerator ensures optimum strength, which was verified/confirmed by the production process [11].

Very good results are achieved in the production of aluminium and non-ferrous alloy castings. We are currently working on the development of binder system for castings made of steel and cast iron [11].

The geopolymer binder system is suitable for most quartz and non-quarts sands such as CERABEADS, olivine sand, chromite sand, aluminosilicate sands. The addition levels are in Tab. 1. The scheme of the core production hardened by heat is shown in Fig. 4 [11].

\section{Experimental procedure}

The new grade of geopolymer binder was used for core production. It is sodium-potassium grade with higher hot and cold strengths, improved humidity resistance and long storage life of cores. The casting of turbocharger no. 3994401523 were chosen by the foundry for the verification of the geopolymer technology. Standard cores made by PUR cold box amin technology directly at the foundry were used as comparison.

The targets of the experiment were as follows:

- Verify the core production in the core machine modified for the hot box and hot air hardening.

- Observation of the technological properties.

- Verification of long storage of cores.

- Application of refractory alcohol based coating.

- Demonstrating the harmlessness of the geopolymer technology throughout the entire production process, especially at pouring and decoring.

- And finally, the main target is casting quality, both the surface and internal casting quality.

\subsection{Materials}

It has already been mentioned, the sodium-potassium type geopolymer W20 was used as the binder. The following materials were used for the core sand mixture:

- $\quad$ quartz sand BK31, AFS 43,

- geopolymer binder W20, sodium-potassium type of geopolymer binder,

- $\quad$ inorganic powder additive, GEOTEK W303.

\subsection{Core production}

The modified core machine was used for the core production at core shop. The heating of the metal core box provide two electrical heated plates which are controlled by independent temperature regulators. The heating power of both electrical plates is $\max 15 \mathrm{~kW}$, maximum working temperature is $250^{\circ} \mathrm{C}$. Hot air is generated by air heater, which is connected on compressed air at 6 bars. The heating power is $\max 12 \mathrm{~kW}(1100 \mathrm{lt} / \mathrm{min})$ and the temperature is possible to set up to $600^{\circ} \mathrm{C}$ (real temperatures up to $200{ }^{\circ} \mathrm{C}$ ). The core shooter with installed turbocharger core box is showwn Fig. 5. The detail of the metal core box is shown on the Fig. 6.

The core sand mixture composition is shown the 
Tab. 2 and the parameters set for the core shooting and hardening are shown at the Tab. 3. The temperature of core box was set on $190{ }^{\circ} \mathrm{C}$, but the real temperature was around the $155^{\circ} \mathrm{C}$. Electrical heating plates continuously heating the core box during the entire core production procedure, in spite of this, small temperature fluctuation in several ${ }^{\circ} \mathrm{C}$. This is caused by hardening of the cores and by cooling of core box when are both halves open and cores are taken from core box. Temperature of hot air is set on $190{ }^{\circ} \mathrm{C}$ and the real temperature is about $145^{\circ} \mathrm{C}$. Shooting pressure was 5,5 to 6.0 bars and hot air pressure 3.0 bars for hardening. Core sand mixture shot to the heated core box was kept 20 seconds and then hardened by purging of hot air for 75 seconds. Totally, 231 cores were produced and 217 supplied to the foundry, cores ready for packing, see Fig. 7. Manufactured cores were stored one week and then packed in core shop as usual and were supplied to the foundry for pouring. There was no core damaged despite of more than $200 \mathrm{~km}$ transport distance.

The cores were stored at the foundry warehouse for another two weeks under standard condition. Just 24 hours before the pouring was the standard alcohol based refractory coating applied by dipping, see Fig. 7. The cores were ready for pouring.

Tab. 2 Core sand mixture composition.

\begin{tabular}{|l|c|c|}
\hline Material & Addition level [wt \%] & Material temperature [ $\left.{ }^{\circ} \mathbf{C}\right]$ \\
\hline BK 31, quartz sand & 100 & $22.1^{\circ} \mathrm{C}$ \\
\hline Geopolymer binder W20, binder & 1.8 & $23.2^{\circ} \mathrm{C}$ \\
\hline W303, powder additive & 0.9 & $23.3^{\circ} \mathrm{C}$ \\
\hline Core sand mixtures was prepared in $15 \mathrm{kgs}$ batches.
\end{tabular}

Tab. 3 Parameters and seting-up the core shooter machine.

\begin{tabular}{|c|c|c|}
\hline Parameter & Set value & Real value \\
\hline Core box temperature & $190^{\circ} \mathrm{C}$ & $155^{\circ} \mathrm{C}$ \\
\hline Time of core sand inside the core box & \multicolumn{2}{|c|}{$20 \mathrm{~s}$} \\
\hline Hot air temperature & $190^{\circ} \mathrm{C} / 170^{\circ} \mathrm{C}$ & $\left(145^{\circ} \mathrm{C}\right)$ \\
\hline Time of hardening by hot air & \multicolumn{2}{|c|}{$50 \mathrm{~s}$} \\
\hline Shooting pressure & \multicolumn{2}{|c|}{$5.5-6.0$ bar } \\
\hline Total working time (from start to start) & \multicolumn{2}{|c|}{$135 \mathrm{~s}$ (two cores in core box) } \\
\hline Hot air pressure & \multicolumn{2}{|c|}{$3.0 \mathrm{bar}$} \\
\hline
\end{tabular}

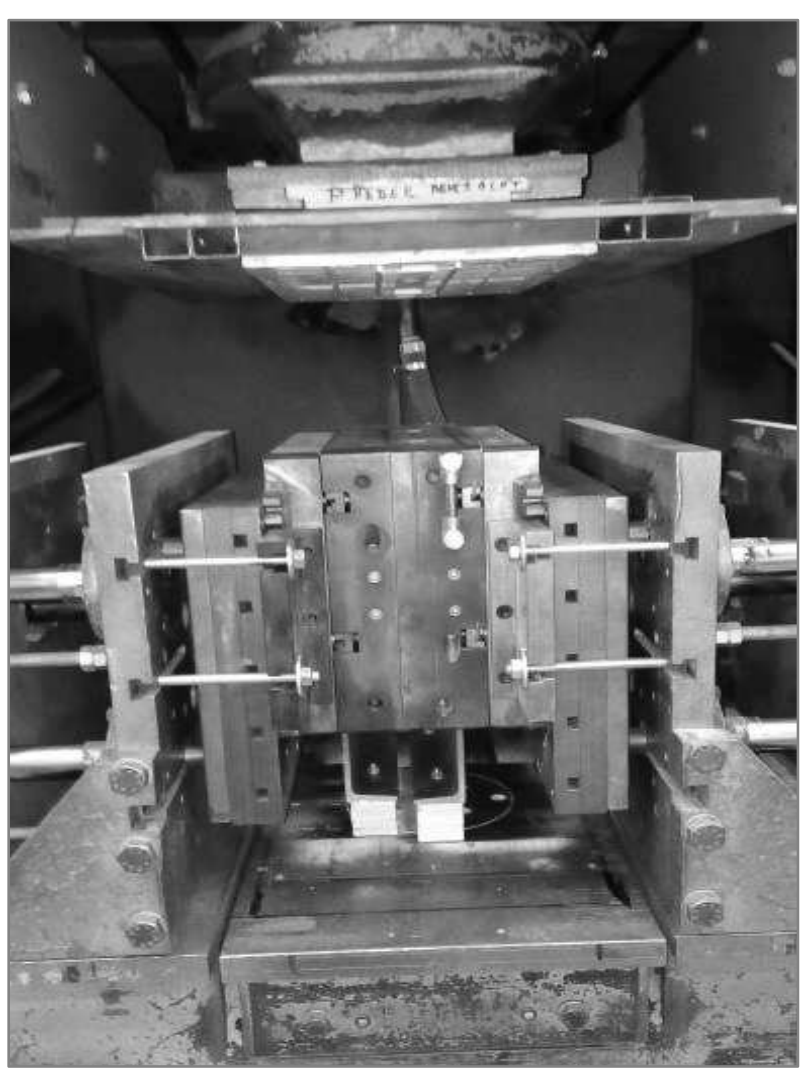

Fig. 5 The core box of turbocharger installed inside the core shooter machine

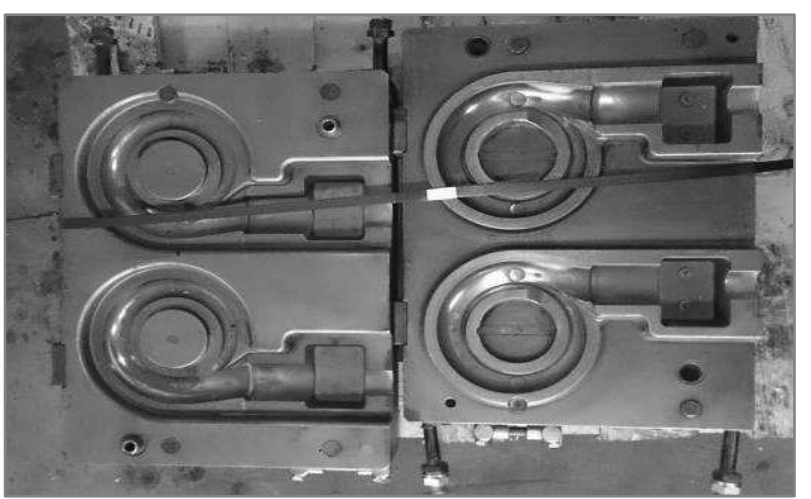

Fig. 6 The steel core box for core production of turbocharger casting no. 3994401523.

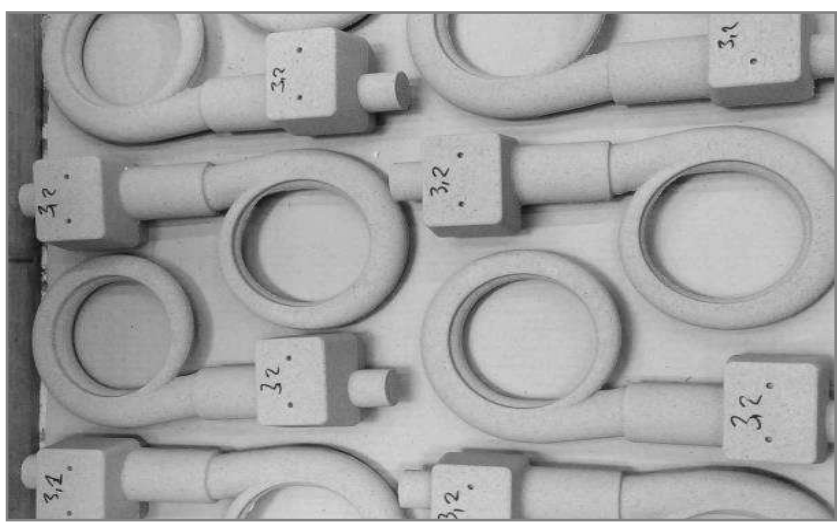

a) 


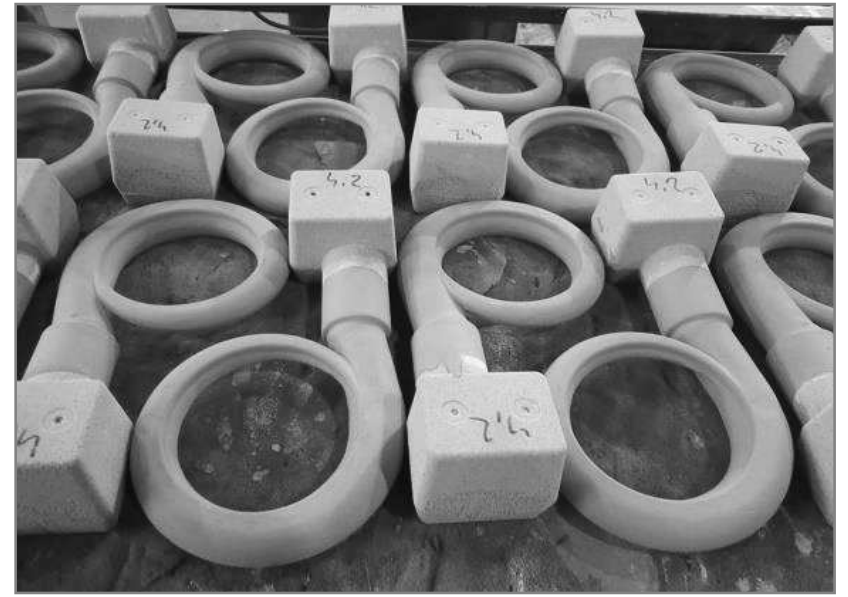

b)

Fig. 7 The final core of turbocharger made bygeopolymer technology (a) and after standard coating (dipping) by alcohol based coating (b)

\subsection{Pouring and decoring}

Pouring machine LPDC internal no. 51 was chosen for casting production due to the current standard production of castings with PUR cold box amin cores. So the machine was in operating temperature and geopolymer cores could be used for pouring immediately without break of production. The mould has two-part, see Fig. 12. The aluminium alloy and the pouring parameters were as follows:

- Aluminium alloy for castings: EN AC-45400.

- Melt temperature: $720 \pm 10^{\circ} \mathrm{C}$.

- Filling pressure: $18 \pm 10 \mathrm{kPa} ; 26 \pm 5 \mathrm{~s}$

- Pressure: $20 \pm 10 \mathrm{kPa} ; 120 \pm 20 \mathrm{~s}$

- Solidification: $120 \pm 20 \mathrm{~s}$

Decoring was carried out by a jackhammer manually according to the standard procedure regularly used in the foundry. As a measure of the break down of the cores is the decoring time (clearing time of the casting). The casting with cores before decoring are possible to see in Fig. 8.

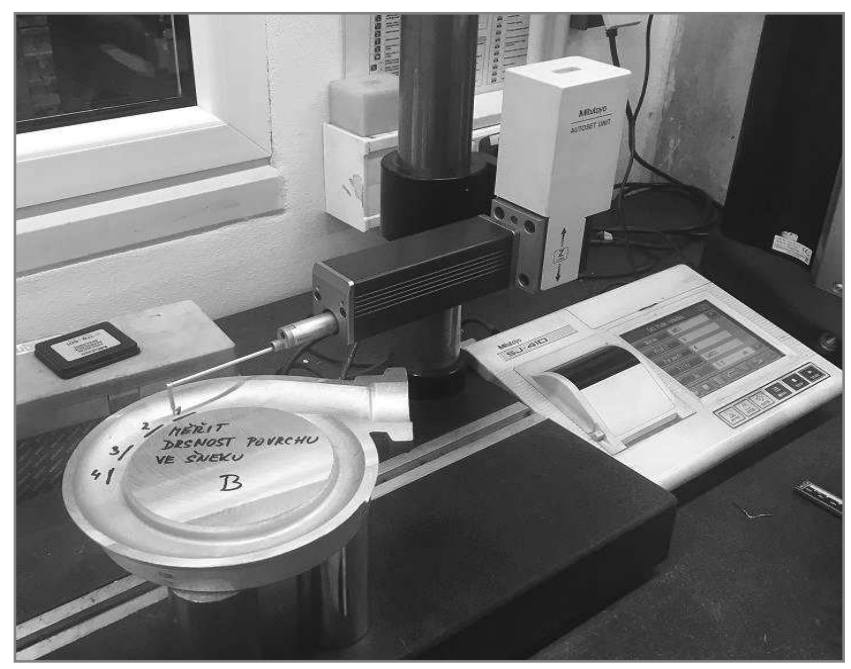

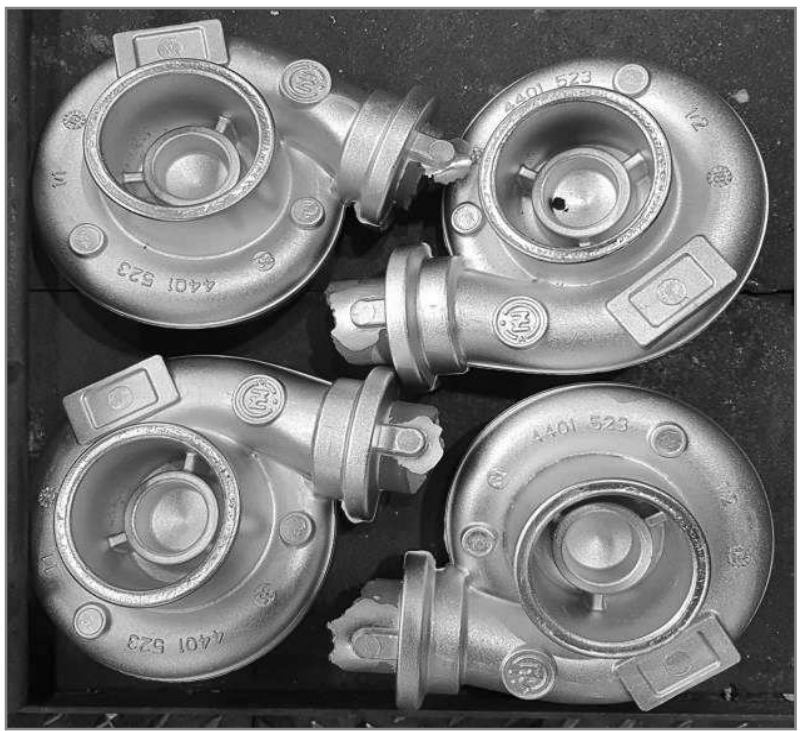

Fig. 8 Castings after removing from the mouid

\subsection{Castings quality evaluation}

Casting quality evaluation was carried out in the foundry.

The principal objective is the comparison of the casting surface made by cores of the existing organic technology PUR cold box amin and the new inorganic geopolymer technology. Laboratory of the foundry has a casting surface roughness measuring device, the Mitutoyo SJ-410 type. The roughness was measured in four points, on same location, see Fig. 9 and Fig. 10. The internal quality of the castings by X-ray examination was also evaluated in the foundry laboratory.

Castings made by the cores of the geopolymer technology were finally tested in the customer laboratory by machining and by pressure test were compared with standard castings made by the cores of the PUR cold box amin.

Considered was the comparative roughness assessment evaluation of the casting surface quality as well according to the measuring set with six pieces of surface sample graded in $\mathrm{Ra}$ or $\mathrm{Rz}$ roughness value in $\mu \mathrm{m}$, see Fig. 11 [12].

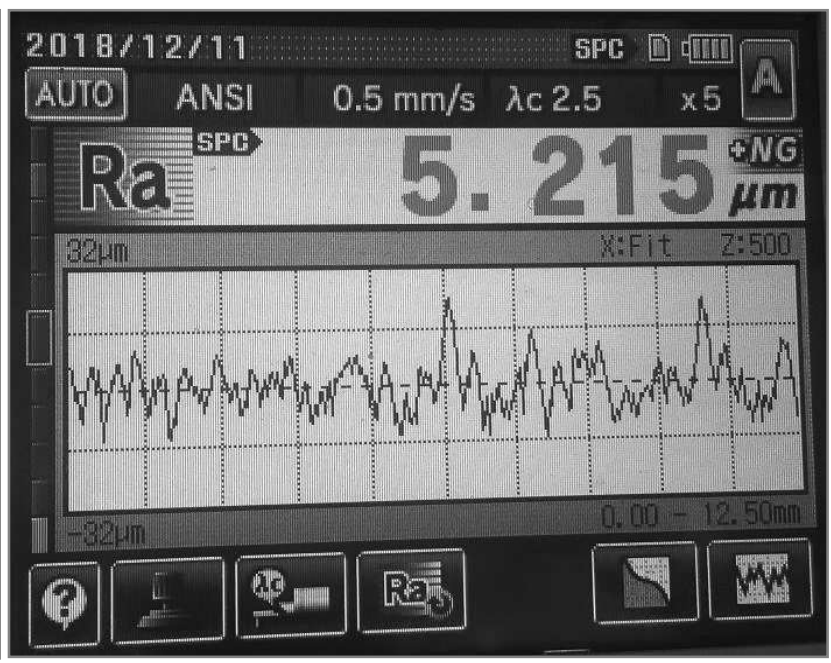

Fig. 9 The surface roughness measuring apparatus Mitutoyo SJ-410 (left) and the record of surface roughness measurement progress (right). 


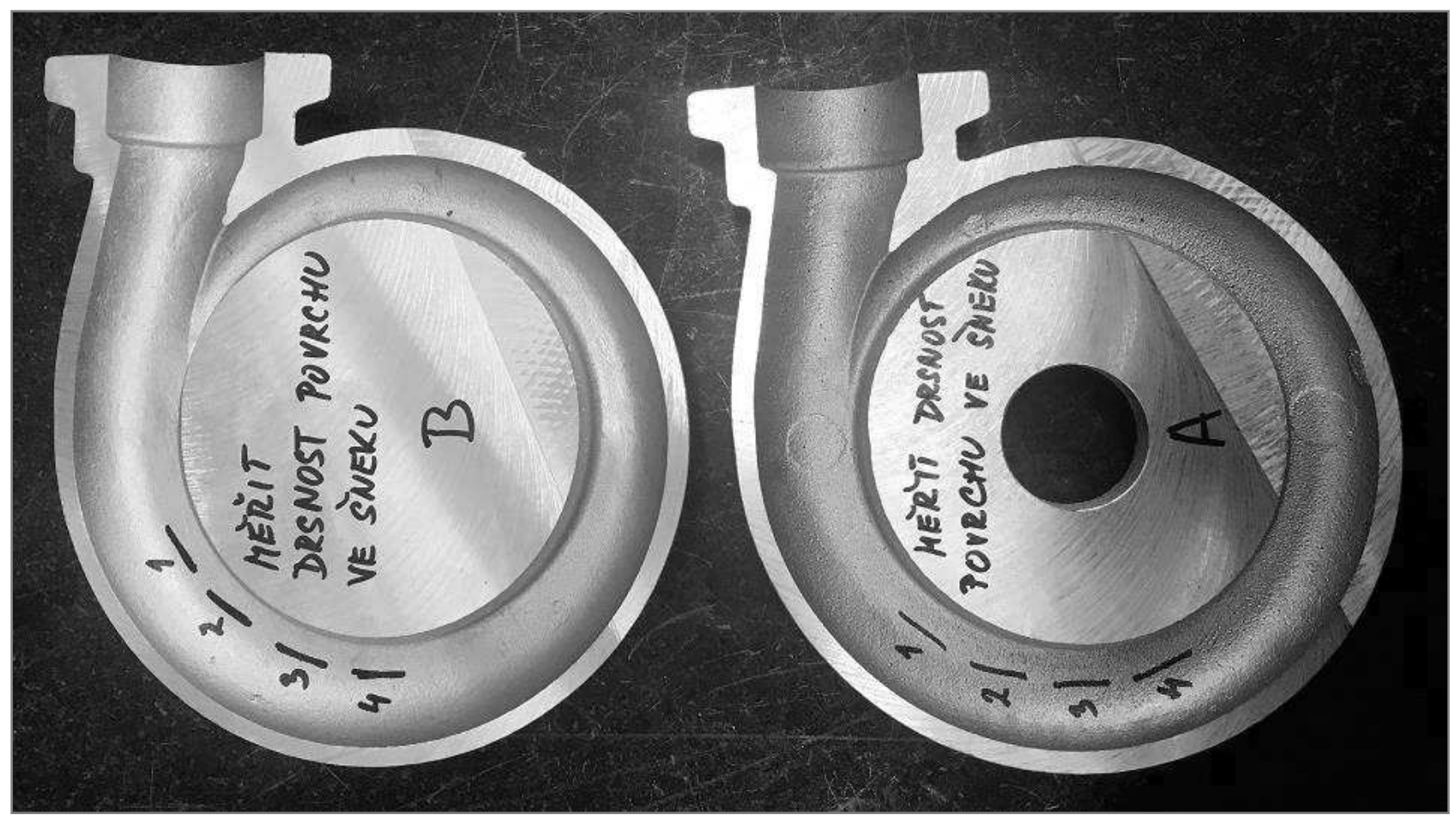

Fig. 10 Casting made in geopolymer binder W20 core (left) and PUR cold box amin core (right, with drilled hole). Numbers 1, 2, 3, 4 indicate areas, where the surface roughness were measured.

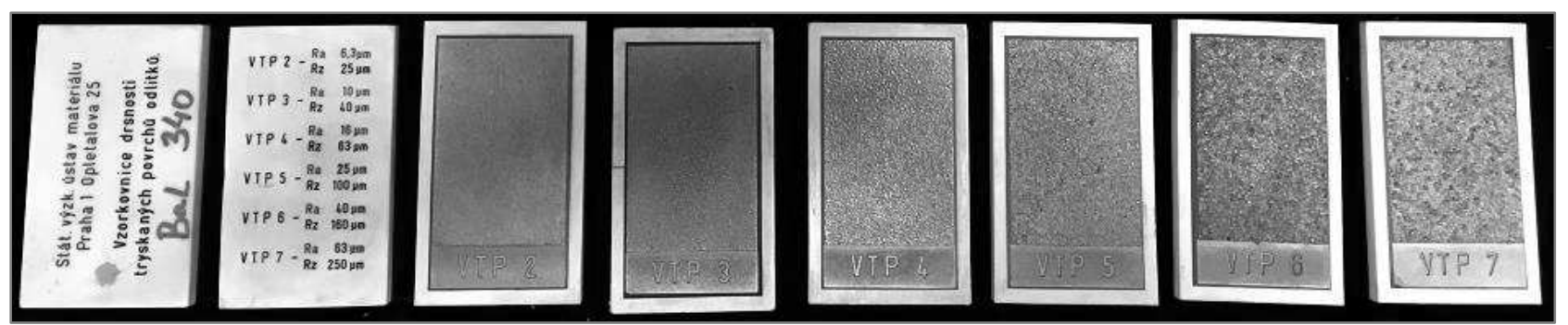

Fig. 11 Comparative roughness assessment [12]

\section{Experimental results}

Tab. 4 presents the flexural strength properties of both geopolymer binder and PUR cold box amin core sand mixtures. Geopolymer binder has higher strengths at presented addition levels, very good strength at $100 \%$ relative humidity and even if the test samples are put into

\subsection{Core production and flexural strength}

water, the strength is still about at $1.9 \mathrm{MPa}$. There is the possibility of changing the addition level depending on applications and requirements on cores and castings.

Tab. 4 The flexural strength properties of geopolymer binder and PUR cold box amin core sand mixtures

\begin{tabular}{|c|c|c|c|c|c|}
\hline \multirow{2}{*}{ Core production technology } & \multicolumn{5}{|c|}{ Flexural strength [MPa] } \\
\cline { 2 - 6 } & $\begin{array}{c}\text { Immediately } \\
\text { (hot strength) }\end{array}$ & After 1 hour & After 24 hours & $\begin{array}{c}\text { After 24 hours } \\
100 \% \text { RH }\end{array}$ & $\begin{array}{c}\text { After } 24 \text { hours } \\
\text { in water }\end{array}$ \\
\hline Geopolymer binder W20 & $\mathbf{4 . 3 0}$ & $\mathbf{4 . 6 0}$ & $\mathbf{5 . 6 0}$ & $\mathbf{4 . 5 0}$ & $\mathbf{1 . 9 0}$ \\
\hline PUR cold box amin * & $3.90^{* *}$ & 4.40 & 4.60 & --- & -- \\
\hline
\end{tabular}

$*$ addition level of PUR cold amin core sand mixture: $0.7+0.7 \%$ (part $1+$ part 2 ).

** flexural strength immediately after amin curing.

The cores made by the geopolymer technology can be manufactured in the same production cycle as the cores made by the PUR cold box amine technology. In this case, the geopolymer cores had 135 seconds total working time (two cores in core box), the PUR cold box amin had about 150 seconds by one cycle. By the optimisation of working procedures could be reached even better times and furthermore improve productivity. The great advantage is, that there is no odour, smell, fume during the entire core production. There has been observed and verified by weighting that the geopolymer cores are heavier than PUR cold box amin cores, about $100 \mathrm{~g}$ (10\% of whole 
core weight). It confirms better compaction of cores and leads to avoid the penetration of aluminium melt and leads to better surface quality.

\subsection{Core storage, storage life, use of coatings}

As was mentioned, geopolymer cores were stored one week in core shop as usual and then stored at the foundry storage for another two weeks under standard conditions. There was no core damaged during storage and handling both in core shop and in foundry and during the transportation to the foundry as well.

The manufactured geopolymer cores do not need any extra care, it means, that conventional coatings can be applied (conventional alcohol based coatings based on graphite or aluminosilicates or corundum or zirconium etc. or their mixtures). Cores were visually fully comparable with PUR cold box amin from point of view core surface quality after coating application. The cores can be stored in standard foundry conditions without having affected the final casting quality. There is no deformation of the cores. The conclusion made in [13] (geopolymer binders might be more sensitive for storage conditions, higher sensitivity for air moisture) were not be confirmed.

\subsection{Pouring}

More favourable effect of the geopolymer binder system on the work environment and the environment can be seen in Fig. 12. The differences between inorganic and organic binder systems are significant. The cores made by geopolymer technology do not generate smoke, fume, odour, and smell during the pouring and at the opening the moulg. Only hardly noticeable aroma is formed.

We positively evaluate the following:

- working times were the same as standard with PUR cold box amin,

- there were no difficulties during pouring,

- there were no breaking of the cores at inserting them to the die or during pouring itself,

- foundryman confirmed: cores were not crumbled, no grains of sand fallen into the die (sand was not adhered on the mould cavity).

Very good collapsibility of the cores after pouring and the substantial reduction of the decoring process time has not been confirmed. The decoring times were $3 \mathrm{x}$ to $4 \mathrm{x}$ longer than standard times. It is the main disadvantage of the experiment and the primary task for the next development and optimization leading to improve whole process especially decoring. The better core break down can solve reduced binder addition level and a new type of additive.
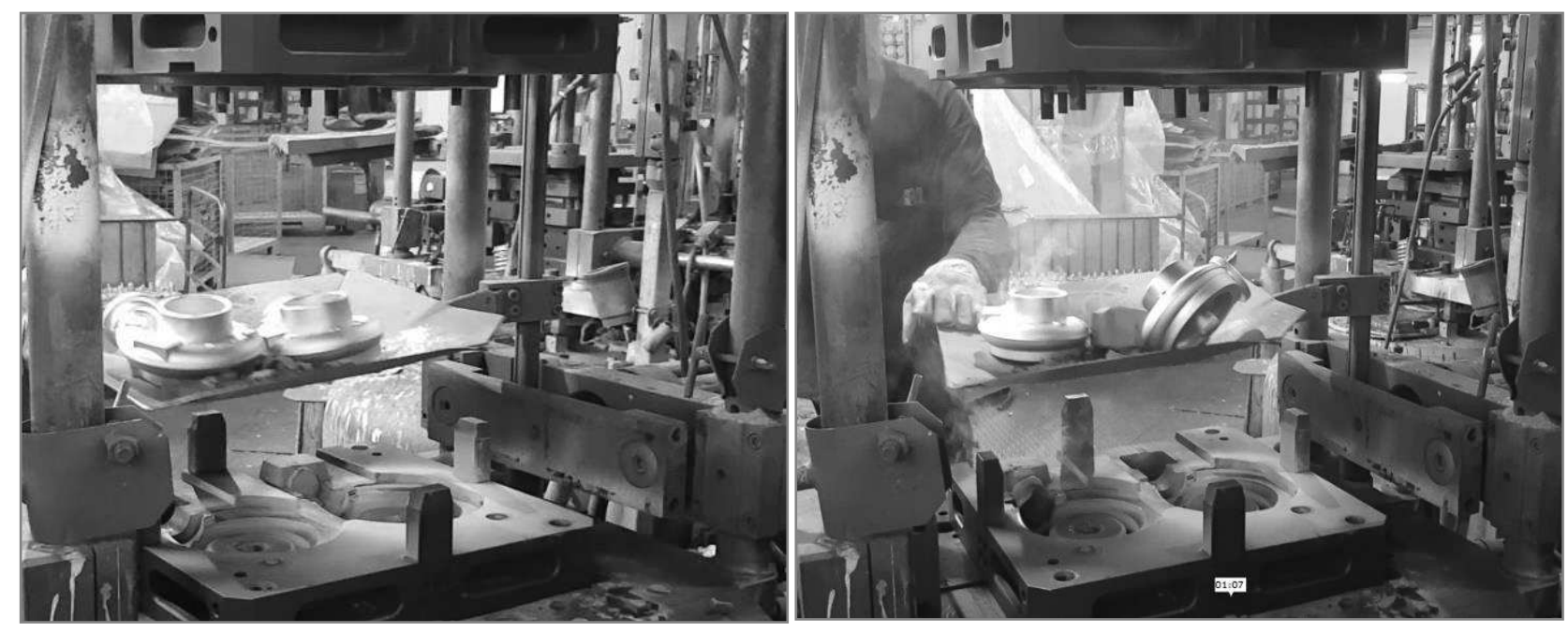

Fig. 12 Comparison of smoke development after opening the mould, there was significant difference, geopolymer cores(left) - no smoke, no smell and cold box amine cores (right) - white and very smelly smoke

\subsection{Castings quality evaluation}

The result values of surface roughness Ra are for both

Tab. 5. Is it possible to see that castings made by geopolymer binder cores have surface roughness Ra from 5.215 to $6.227 \mu \mathrm{m}$ in comparison with values from 12.573 to $29.178 \mu \mathrm{m}$ by PUR cold box amin cores. Higher values of surface roughness are in central area of castings for both technologies. It could be stated that castings made by geopolymer cores reach three times lower surface roughness values. The difference in favour of geopolymer binder can be seen on the details of castings surface, Fig. 13. These are very positive results. The good results can be related with less gasses formed during pouring and castings made by geopolymer binder and PUR cold box amin cores shown in the

higher compaction of geopolymer cores.

The Fig. 14 presents X-ray examination pictures of casting for both technologies. It could be stated that there is no difference and castings made by both technologies are without internal defects.

Successfully were castings tested in the customer laboratory. The machining and pressure test were made as standard and all 41 castings were classified as OK.

It would be very interesting to use for standard production cores without refractory coating. It could be economical benefit and less handling and time savings in 
case of successful results. It can be subject of next exper-

iment.

Tab. 5 Surface roughness from the core side made in geopolymer binder W20 and additive W303 and comparison with PUR cold box amin.

\begin{tabular}{|c|c|c|c|}
\hline \multicolumn{2}{|c|}{ Surface roughness from the core side, Ra [ $\boldsymbol{\mu m}]$} & \multirow{2}{*}{ Multiple } \\
\hline Measured surface & PUR cold box amin & Geopolymer binder & $2.45 \mathrm{x}$ \\
\hline 1 & 12.795 & $\mathbf{5 . 2 1 5}$ & $2.02 \mathrm{x}$ \\
\hline 2 & 12.573 & $\mathbf{6 . 2 2 7}$ & $3.87 \mathrm{x}$ \\
\hline 3 & 22.973 & $\mathbf{6 . 0 7 7}$ & $4.96 \mathrm{x}$ \\
\hline 4 & 29.178 & $\mathbf{5 . 8 7 7}$ & $\mathbf{3 . 3 1 x}$ \\
\hline
\end{tabular}
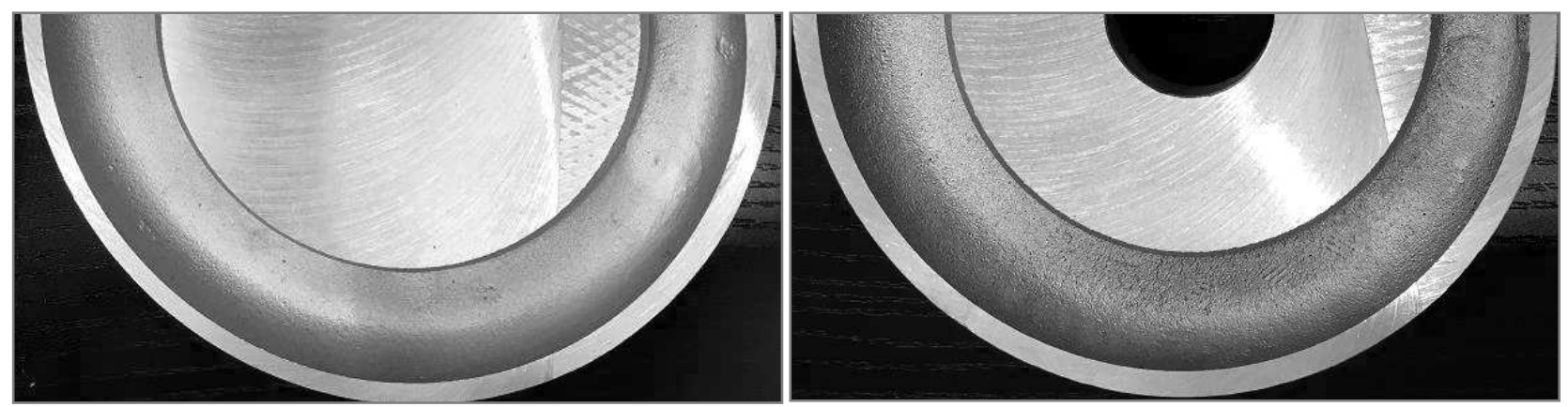

Fig. 13 Details of casting surface. Much better surface on left castings made in geopolymer binder. Core made by PUR cold box amin provides worse final casting surface (right, with drilled hole).
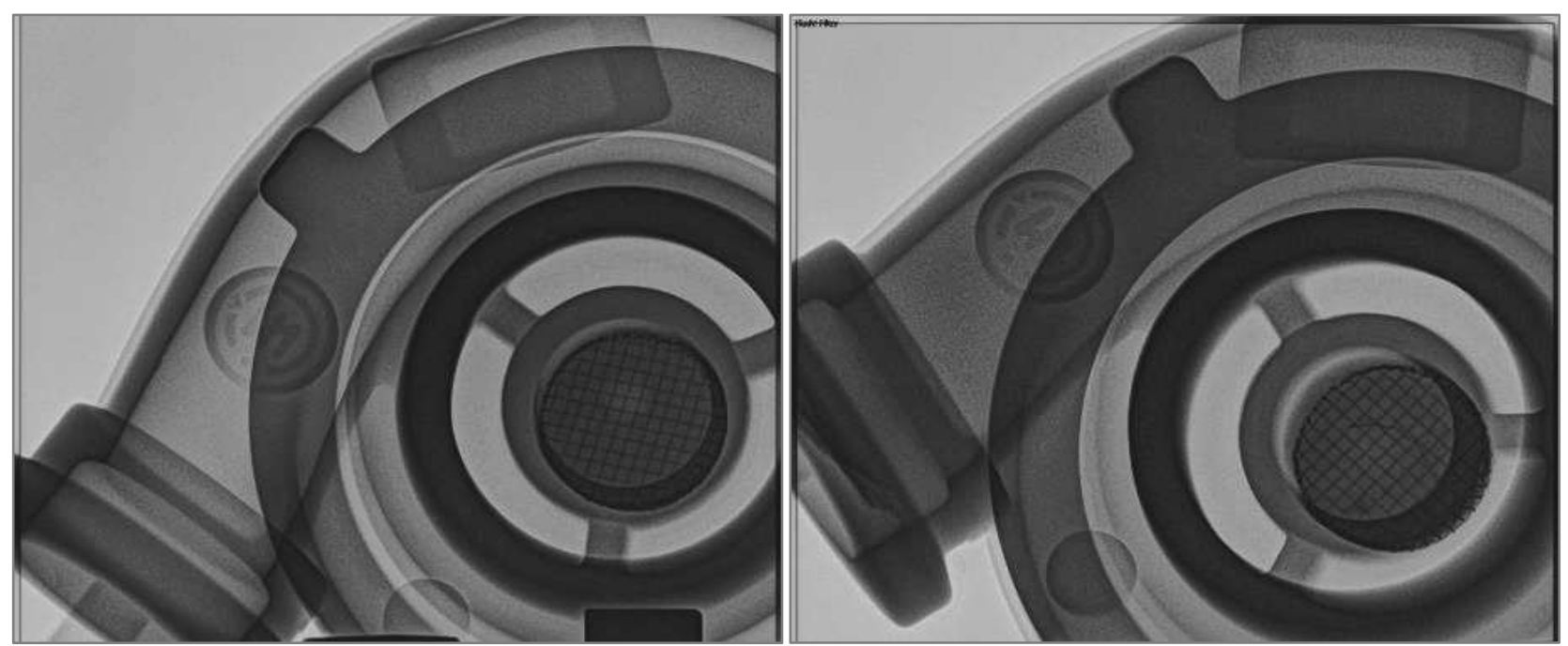

Fig. 14 X-ray examination pictures of both castings (cores made by geopolymer and PUR cold box amin technology (It is obvious that both castings are free of internal defects).

\section{Conclusion}

The presented research paper and obtained results support and confirms the effort to introduce the geopolymer technology, geopolymers and inorganic binders for core production and with goal to replace the organic binders in short future. The new sodium-potassium geopolymer grade, binder W20, seems to be as the right way. The final surface and internal castings quality confirm it.

Obtained results are compared with PUR cold box amin widely used at foundries. Can be argued that the geopolymers have great possibility in the field of core production. The geopolymer technology is completely inorganic. Geopolymers for hot box and hot air hardening can guarantee good core and casting production with the same or better productivity and mainly much more environmental friendly during the whole core and casting production.

On the basis of the results, the following conclusions can be summarized:

- Flexural strength of the geopolymer core sand mixture is higher or the same than the PUR cold box amin, depending on addition level. This means that the geopolymer technology is an adequate alternative from the viewpoint of strength.

- Cores can be manipulated as usual and the conventional refractory coatings can be used as well. 
- All cores were stored under standard conditions almost one month without any problems, strength reduction, any abrasion. No special conditioned room, tent or extra care is needed.

- Very positively could be seen impact to working conditions and environment generally. No smell, smoke, fume, or hazardous odour are not generated throughout the production process, even during pouring and decoring.

- The break down was identified as the weak property in this research despite very good break down properties observed in similar experiments. This disadvantage can be solved by the reduced amount of binder in the core sand mixture, the high flexural strength allow this binder reduction or usage of new types of additive which improve the core break down after pouring.

- Internal quality of castings evaluated by X-ray examination demonstrate castings without any defects.

- A significant difference was observed in the evaluation of the casting surface roughness from the core side. The roughness made by geopolymer binder core was three times lover than PUR cold box amin. It gives the possibility to use the cores without refractory coatings in standard production process, which can improve productivity, save costs and handling and storage capacity.

- Final machining and pressure test at the customer were evaluated positively for all castings.

\section{Acknowledgement}

This work was developed as part of solution of the project TA04011039, Foundry cores with the geopolymer binder supported by Technology Agency of the Czech Republic and as part of the project CZ.01.1.02/0.0/0.0/16_084/0010119, Research of new technology of foundry moulds in self hardened mixtures with geopolymer binder system within the APLIKACE project. We thank for their support.

\section{References}

[1] DAVIDOVITS, J. (2015). Geopolymer Chemistry and Application, Vols. 4th edition, November 2015, Saint-Quentin: Institut Géopolymére, SaintQuentin. France.
[2] GLUCHOVSKIJ, V. (1959). Soil-Silicate Concrete (Gruntosilicates), Kiev.

[3] VYKOUKAL, M., BURIAN, A., PŘEROVSKÁ, M. (2017). Inorganic binder systems in the past, at present and in the future. In: Slévárenství. No. 11 - 12, pp. 361 - 374. Czech Republic.

[4] DAVIDOVITS, J. (2005). The poly(sialate) terminology : a very useful and simple model for the promotion and understanding of green-chemistry. In: Geopolymer chemistry and sustainable development solutions. Proceedings of the World Congress Geopolymer 2005. ISBN 2-9524820-0-0, Saint-Quentin. France.

[5] DAVIDOVITS, J. (2006). The Pyramids: An Enigma Solved, Fontána. Czech Republic.

[6] BARBOSA, V. F., MACKENZIE, K. J., THAUMATURGO, C. (2000). Synthesis and characterisation of materials based on inorganic polymers of alumina and silica: sodium polysialate polymers. In: International Journal of Inorganic Materials, pp. $309-317,22000$.

[7] ROWLES, M., HANNA, J., PIKE, K., SMITH, M., O'CONNOR, B. 2007. 29Si, 27Al, $1 \mathrm{H}$ and $23 \mathrm{Na}$ MAS NMP study of the bonding character in aluminosilicate inorganic polymers. In: Applied Magnetic Resonance, No. 32, pp. 663 - 689.

[8] VYKOUKAL, M., BURIAN, A., PŘEROVSKÁ, M., KUBEŠ, P. (2016). Cores hardened by heat operational experiences with trial of binder system GEOPOL ${ }^{\circledR} \mathrm{W}$ in the foundry BENEŠ a LÁT, a.s. In: Slévárenství, No. 7 - 8, pp. 236 - 239. Czech Republic.

[9] HOLTZER, M., KMITA, A., DAŃKO, R. (2015). The gases generation during thermal decomposition of moulding sands - comparison of inorganic and organic binders. In: Slévárenství, No. $7-8$, pp. 240 - 247, LXIII. Czech Republic.

[10] Inorganic binder system GEOPOL ${ }^{\circledR}$. (2016). Catalogue, SAND TEAM, spol. s r.o., v1/14.10.2016. Czech Republic.

[11] Internal documentation, results of research and development and production instructions of company SAND TEAM, spol. s r.o., Holubice. Czech Republic.

[12] Surface roughness set, Praha: SVÚM.

[13] VASKOVÁ, I., CONEV, M., HRUBOVČÁKOVÁ, M. (2018). Technological Properties of Moulding Sands with Geopolymer Binder for Aluminium Casting. In: Archives of Foundry Engineering, Volume 18, Issue 4, Vols. ISSN (1897-3310), pp. 45 - 49. Poland. 